\title{
Adsorption kinetics and equilibrium of phenol drifts on three zeolites
}

Research article

Bachar Koubaissy ${ }^{1 *}$, Joumana Toufaily ${ }^{1,2}$, Maya El-Murr ${ }^{1}$, T. Jean Daou ${ }^{3}$, Hala Hafez ${ }^{1}$, Guy Joly ${ }^{4}$, Patrick Magnoux ${ }^{4}$, Tayssir Hamieh ${ }^{1}$

1 Laboratory of Materials, Catalysis, Environment and Analytical Methods, Lebanese University, Rafic Hariri Campus, Beirut, Lebanon

2 School of Mechanical and Materials Engineering, Washington State University, Pullman, WA 99164, United States of America

3 Equipe Matériaux à Porosité Contrôlée, Institut de Science des Matériaux de Mulhouse, ENSCMu - Université de Haute Alsace LRC CNRS 7228, 3 rue Alfred Werner, 68093, Mulhouse Cedex, France

4 Laboratoire de Catalyse en Chimie Organique, Faculté des Sciences, Université de Poitiers, UMR CNRS 6503, 40 Avenue du recteur Pineau, 86022 Poitiers Cedex, France

Received 19 November 2011 ; accepted 08 March 2012

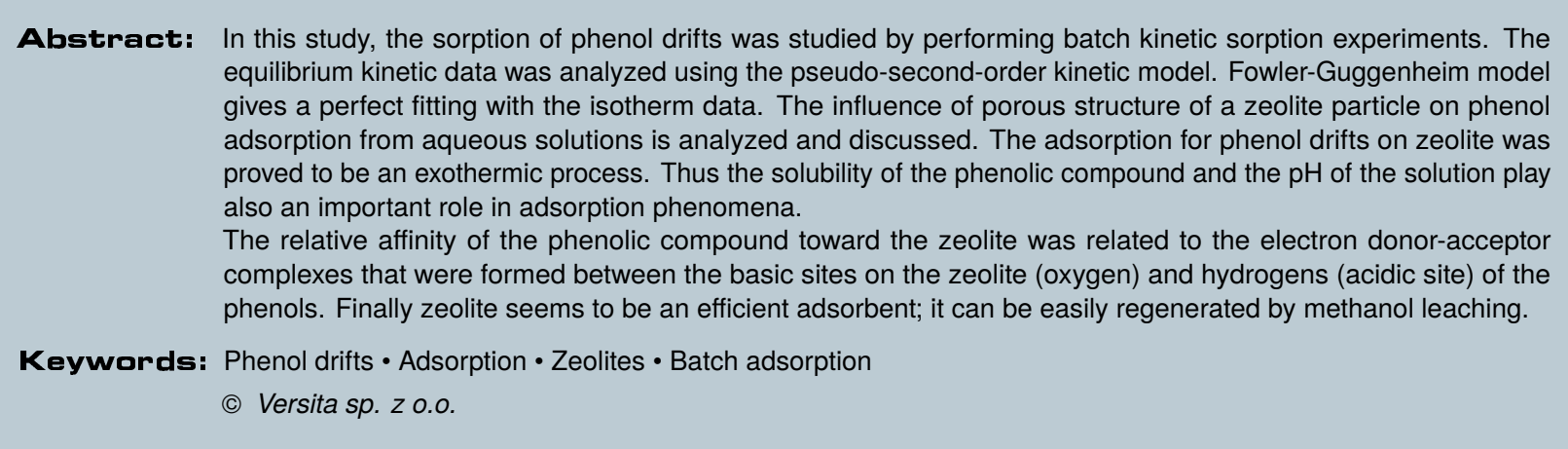

\section{Introduction}

With the development of the industry and the intensive use of pesticides, wastewater discharges have evolved considerably in quantity and quality. Phenols and related compounds present in wastewater are toxic to humans and aquatic life [1-3]. Therefore, organizations of health and

*E-mail: bachar.kobaissy@ul.edu.lb the environment issue instructions to set the maximum allowable levels of pollutants. As a result, great research efforts on adsorption processes and adsorbent materials for separating organic pollutants from waste streams have been developed [4-6].

Activated carbon is the most widely used adsorbent for water treatment, however, regeneration is difficult and expensive $[7,8]$. This has led many laboratories to focus on research of new, efficient and regenerative adsorbents $[6,9,10]$. 
Zeolites have been recently noted as a practical alternative to activated carbon because of their high surface area, their high selectivity and their economic cost for regeneration after saturation $[11,12]$.

In this work, three kinds of zeolites are used: a Faujasite type (HFAU) partially dealuminated, Mordenite type (HMOR) and a Beta type (HBEA). HFAU consists of sodalite cages which are connected through hexagonal prisms. The pores are arranged perpendicular to each other. The pore, which is formed by a 12-membered ring, has a relatively large diameter of $7.4 \AA$. The inner cavity has a diameter of $12 \AA$ and is surrounded by 10 sodalite cages. HMOR structure is a framework containing chains of fivemembered rings of linked silicate and aluminate tetrahedral. These building units are linked by edge-sharing into chains along $c$, which are in turn linked together by 4-rings to form a puckered sheet perforated with 8-ring holes. These permeable sheets are oriented parallel to [010]. Linking these sheets together with 4-rings, 12-ring channels are formed parallel to [001]. The 8-ring holes of successive sheets do not align to make channels parallel to [010]. Beta type (HBEA) can be regarded as a highly internally grown hybrid of two distinct (polymorph $A$ and B) but closely related structures that both have fully threedimensional pore systems with 12 membered ring diameter of 5.6-6.7 $\AA$.

The physicochemical mechanisms in these materials are complex [13]; no simple theory of adsorption could adequately describe experimental results.

Electrostatic and van Der Waals forces, H-binding, dipole-dipole interactions, ion exchange, covalent bonding, cation bridging and water bridging can be responsible for adsorption of organic compounds in zeolites [13-15].

The equilibrium adsorption isotherm is of importance in the design of adsorption systems. Several isotherm equations are available and one isotherm is selected in this study: the Fowler-Guggenheim adsorption model [16].

Batch studies were carried out to identify the rate controlling steps. Many adsorption kinetics models of singlesolute were reported in the literature. For example, Mass transfer classical model [17], Intra-particular diffusion [18] and External diffusion [19]. In our study, the pseudo second order $[20,21]$ will be used to fit the adsorption kinetics data.

The objective of this work is to study the removal of various organic compounds (phenol, 2-chlorophenol, 2-nitrophenol and salicylic acid) in water over zeolites by comparing the influence of their physicochemical properties. Adsorption was conducted in a batch apparatus, and the effect of $\mathrm{pH}$ was studied. Furthermore, we have tried to highlight the influence of the structure of the zeolite on adsorption of these pollutants. The effect of temperature and the size of porous were also investigated.
On the other hand, our study was carried out to identify the Kinetic parameters of the sorption of phenol drifts and to specify the rate constants and other parameters for the application of zeolites in water treatment.

\section{Experimental part}

\subsection{Zeolites Adsorbents}

Partially dealuminated HFAU zeolite and BEA zeolite were supplied by Zeolyst International, HMOR samples were provided by Institut Regional des Matériaux Avancés (IRMA) Ploemeur-France. Si/Al ratio were determined using an X-ray fluorescence spectrometer MagiX (Philips) on pellets composed of $200 \mathrm{mg}$ of compacted product ( $\mathrm{Ta}-$ ble 1). The adsorbent structure before and after adsorption was determined by Powder X- Ray Diffraction (XRD) on Brucker D8 Advanced diffractometer with $\mathrm{CuK} \alpha$ radiation $(\lambda=1.5406 \AA)$.

The surface functional groups and adsorptive form of organic compounds were identified using IR spectroscopy. The measurements were recorded using a Bruker IFS66S with a Bruker SpectraTech Baseline DRIFT module, for doing DRIFT (Diffuse Reflectance Infrared Fourier Transform) spectra. DRIFT spectra were recorded between 4000 and $600 \mathrm{~cm}^{-1}$.

The microporous and mesoporous volume and the specific surface area were determined from nitrogen adsorption isotherms at $77 \mathrm{~K}$ on a Micromeritics ASAP 2410 porosimetre using the BET method (on a linear $\mathrm{P} / \mathrm{P}^{0}$ domain between 0.01 and 0.3 ) and the single-point method at $P / P^{0}=0.26$. The calcined samples were placed in a glass measurement cell, and then they were degased at $350{ }^{\circ} \mathrm{C}$ under vacuum prior to the measurement. Thermogravimetric and differential thermal analyses (TGA and DTA) were performed in flowing air using a Setaram Labsys thermoanalyser. Powders were heated at a rate of $3^{\circ} \mathrm{C} \cdot \mathrm{min}^{-1}$ up to $700^{\circ} \mathrm{C}$, and were cooled down to room temperature. The characteristics of zeolite samples are given in Table 1.

\subsection{Adsorbates}

Phenol, 2-chlorophenol, 2-nitrophenol and salicylic acid were purchased from Aldrich. The solutions were prepared using distilled water. The main physiochemical properties of these compounds are featured in Table 2.

\subsection{Adsorption experiments}

Adsorption experiments were carried out using the batch method for different initial phenol drifts concentrations. For each flask, a fixed amount of adsorbent was added to 
Table 1. Characterization of the Zeolite Samples.

\begin{tabular}{|c|c|c|c|c|c|c|}
\hline \multirow[t]{2}{*}{ Adsorbent } & \multirow[t]{2}{*}{ Formula } & \multirow{2}{*}{$\begin{array}{c}\text { Pore size } \\
(\AA)\end{array}$} & \multirow[t]{2}{*}{$\mathrm{Si} / \mathrm{Al}$} & \multirow{2}{*}{$\begin{array}{l}\text { SBET } \\
\left(\mathrm{m}^{2} / \mathrm{g}\right)\end{array}$} & \multicolumn{2}{|c|}{ Pore volume $\left(\mathrm{cm}^{3} \cdot \mathrm{g}^{-1}\right)$} \\
\hline & & & & & micropore & mesopore \\
\hline $\mathrm{HBEA}_{19}$ & $\mathrm{H}_{3.2} \mathrm{Al}_{3.2} \mathrm{Si}_{60.8} \mathrm{O}_{128}$ & $6.6 * 6.7$ and $5.6 * 5.6$ & 19 & 650 & 0.244 & 0.083 \\
\hline $\mathrm{HMOR}_{18}$ & $\mathrm{H}_{2.6} \mathrm{Al}_{2.6} \mathrm{Si}_{45.4} \mathrm{O}_{96}$ & $6.5 * 7$ and $2.6 * 5.7$ & 18 & 530 & 0.174 & 0.084 \\
\hline $\mathrm{HFAU}_{19}$ & $\mathrm{H}_{9.6} \mathrm{~A}_{9.6} \mathrm{Si}_{182.5} \mathrm{O}_{384}$ & $7.4 * 7.4$ & 19 & 740 & 0.245 & 0.11 \\
\hline
\end{tabular}

Table 2. Physicochemical properties of Chemicals.

\begin{tabular}{|c|c|c|c|c|}
\hline Molecules & & & & \\
\hline Purity & $99 \%$ & $98 \%$ & $98 \%$ & $99 \%$ \\
\hline IUPAC Name & Phenol & 2-chlorophenol & 2-nitrophenol & Salicylic Acid \\
\hline Symbol & $\mathrm{PHOH}$ & $\mathrm{OCP}$ & ONP & SA \\
\hline Chemical formula & $\mathrm{C}_{6} \mathrm{H}_{6} \mathrm{O}$ & $\mathrm{C}_{6} \mathrm{H}_{5} \mathrm{ClO}$ & $\mathrm{C}_{6} \mathrm{H}_{5} \mathrm{NO}_{3}$ & $\mathrm{C}_{7} \mathrm{H}_{6} \mathrm{O}_{3}$ \\
\hline$\lambda(\mathrm{nm})$ & 270 & 216 & 276 & 207 \\
\hline Solubility Water ${ }^{a}$ & 87 & 28.5 & 1.26 & 2 \\
\hline $\mathrm{pKa}$ & 9.95 & 8.49 & 7.17 & 2.97 \\
\hline Kinetic diameter $\left(\mathrm{A}^{\circ}\right)^{b}$ & 6.7 & 8.1 & 8.1 & 8.4 \\
\hline
\end{tabular}

${ }^{a}$ Measured at $20^{\circ} \mathrm{C}$ and $\mathrm{pH}=6$

${ }^{b}$ Kinetic diameters for different compounds are calculated using the software "Cerius ${ }^{2 "}$

$100 \mathrm{~mL}$ phenols solution. The initial $\mathrm{pH}$ of the solution was adjusted using $1 \mathrm{~mol} / \mathrm{L} \mathrm{HCl}$ or $\mathrm{NaOH}$ solutions to $\mathrm{pH}$ between 2 and 10 . The flasks were agitated and incubated in an incubator shaker at different temperatures until reaching equilibrium. Samples were taken from the flasks at regular time intervals for analyzing the concentration phenol drifts in the solution. The residual amount of phenol drifts in each flask was investigated using UVIVIS spectrophotometer at different $\lambda$ depending on the phenol drift used (Table 2).

The amount adsorbed of the adsorbates can be calculated by the following equation:

$$
m_{A}(Q)=V\left(C_{0}-C\right)
$$

where

$m_{A}$ : mass of zeolite $(\mathrm{g})$

$V$ : volume of solution $(\mathrm{L})$;

$C$ : concentration after adsorption $\left(\mathrm{mg} \cdot \mathrm{L}^{-1}\right)$;

$C_{0}$ : initial concentration $\left(\mathrm{mg} \cdot \mathrm{L}^{-1}\right)$;

$Q$ : amount adsorbed $\left(\mathrm{mg} \cdot \mathrm{g}^{-1}\right.$ of zeolite).

\subsection{Kinetics models}

The real challenge in the adsorption field is to identify the adsorption mechanism. Therefore a study of the adsorption kinetics is important since the kinetics describe an uptake rate of adsorbate which in turn helps to predict the adsorption mechanism.

The adsorption kinetics may be governed by different diffusion steps as: external diffusion, intra-particular diffusion, adsorption kinetics governed by the surface reaction.

\subsubsection{Intra-particular diffusion}

The equation of Intra-particular diffusion models derivates from Weber and Morris model [18] is expressed as:

$$
q_{t}=\left(\frac{V}{m}\right) K_{w} t^{\frac{1}{2}}
$$

$q_{t}$ : adsorption capacity of zeolite at $\mathrm{t}$

$m$ : adsorbent mass $(\mathrm{g})$

$V$ : solution volume $(\mathrm{L})$

$K_{w}$ : diffusion constant of intra-particular (from Weber and Morris)

$t$ : time

\subsubsection{Pseudo-first-order model}

It was intuitively associated with the model of one-siteoccupancy adsorption kinetics governed by the rate of surface reaction [22]. This model did not perfectly fit our results. It is expressed as:

$$
\frac{d q_{t}}{d t}=K\left(q_{e}-q_{t}\right)
$$


The integrated form of the differential equation becomes

$$
\ln \left(q_{e}-q_{t}\right)=\ln q_{e}-K t
$$

\subsubsection{Pseudo second order model}

The pseudo-second order kinetic equation was proposed by Blanchard et al. [21] and is also based on the sorption capacity of the solid phase and is expressed as:

$$
\frac{d q_{t}}{d t}=K\left(q_{e}-q_{t}\right)^{2}
$$

If second-order kinetics is applicable, the plot of $t / q$ against $t$ should give a linear relationship.

\subsection{5. Adsorption isotherms model}

Several mathematical models can adequately describe the adsorption isotherms, and thus obtain information on the maximum adsorption capacity or different types that take place during the adsorption. Our isotherms have been successfully described by Fowler Guggenheim following the equation [16]:

$$
K C=\frac{\theta}{1-\theta} \exp \left(\frac{2 \theta W}{R T}\right)
$$

where

$K$ : equilibrium constant for adsorption of the adsorbate on an active site;

$C$ : concentration at equilibrium adsorption;

$W$ : empirical interaction energy between two molecules adsorbed on nearest neighboring sites;

$R$ : ideal gas constant $\left(8.314 \mathrm{~J} \cdot \mathrm{mol}^{-1} \cdot \mathrm{K}^{-1}\right)$;

$T$ : thermodynamic temperature;

$\theta$ : fractional coverage of the surface.

Fowler-Guggenheim equation is taking into account the lateral interaction. This model is based on the hypothesis that interaction energy is constant and independent of fractional coverage of the surface $\theta$, and; hence, the number and distribution of adsorbed molecules.

\section{Results and discussion}

\subsection{Effect of initial pH on phenol drifts ad- sorption}

The study of adsorption of phenol on HFAU zeolite was performed at room temperature and under atmospheric pressure with concentration of $1 \mathrm{~g} / \mathrm{L}$ for $\mathrm{pH}$ values between 2 and 10 . The choice of this $\mathrm{pH}$ range is carried out to

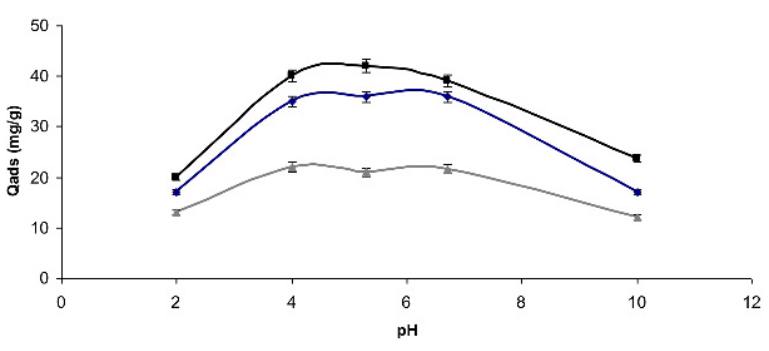

Figure 1. Influence of $\mathrm{pH}$ on phenol adsorption over HBEA ( $\boldsymbol{\square})$, HFAU (४) and $\operatorname{HMOR}(\boldsymbol{\Delta})$.

examine the evolution of the adsorption of solute associated with the different chemical forms which are presented, depending on $\mathrm{pH}$.

Figure 1 shows the effect of solution $\mathrm{pH}$ on the adsorption of phenol on the HBEA, HFAU and HMOR zeolites at given conditions. Adsorption has been increased with increasing $\mathrm{pH}$ up to 4.0 , then between ( 4 and 7 ) the adsorption capacities of phenol were nearly identical; finally, decreasing adsorption of phenol with increasing $\mathrm{pH}(\mathrm{pH}$ 7-10). The maximum adsorption of phenol occurred normally when $\mathrm{pH}$ was lower than its pKa (9.89), at which phenol is present in the neutral form. Phenol is an acidic molecule, so an increasing $\mathrm{pH}$ results in an increasing anionic fraction in solution and; hence, a decreasing adsorption.

Dursun et al. [23] indicated that, phenol and its derivatives adsorb on activated carbon via a "donor-acceptor complex". In our case this mechanism involves siloxane group $\mathrm{Si}-$ oxygen groups acting as electron donor, and the hydrogen bond as acceptor.

The low $\mathrm{pH}$ value was obtained by using an acid solution. It introduced additional protons in the solution, which competed for the Siloxan ( $\mathrm{Si}-\mathrm{O}-\mathrm{Si}$ ) sites. The decrease in phenol adsorption from $\mathrm{pH}=5.3$ to 2 was due to the increased $\mathrm{H}^{+}$adsorption on the siloxan sites, which suppresses phenol adsorption on these sites. On the other hand, the decrease in the phenol amount adsorbed from $\mathrm{pH}=6.7$ to 10 was attributed to both greater solubility of dissociated phenol at $\mathrm{pH}>\mathrm{pKa}$ and increased repulsion forces between the dissociated form of the adsorbate and the zeolite surface.

On the other hand, HBEA zeolite appears more efficient than HFAU and HMOR for adsorption of phenol, the discussion is presented in part 3.5.

\subsection{Phenol drifts isotherms obtained over HFAU and HBEA}

We then studied the adsorption of various derivatives of phenol over different types of zeolites at various $\mathrm{pH}$ values and compared it with the results obtained for phenol ad- 


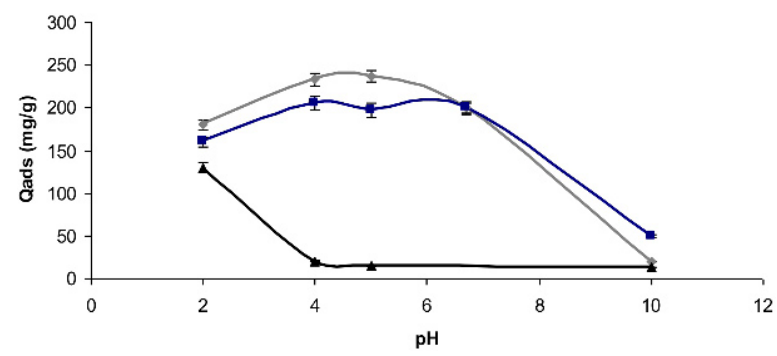

Figure 2. Influence of $\mathrm{pH}$ on phenol drifts adsorption ( $)$ ONP, OCP and (ム) SA over HBEA.

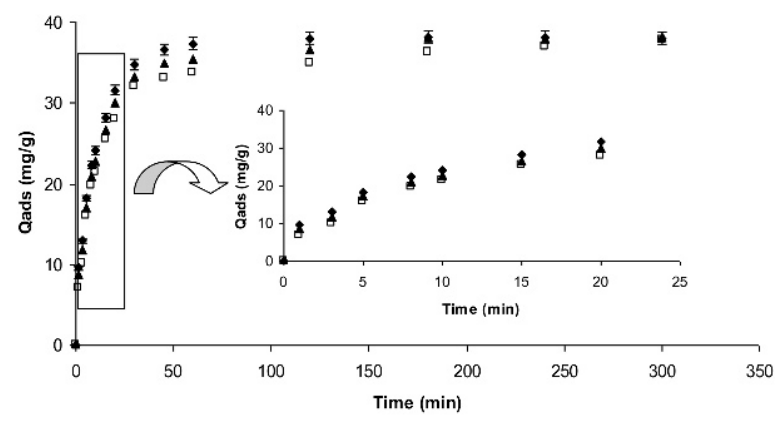

Figure 3. Effect of particles size on phenol adsorption over HBEA zeolite of $0.05-0.07 \mathrm{~mm}(\downarrow), 0.2-0.4 \mathrm{~mm}(\boldsymbol{\Delta})$ and $0.6-0.7 \mathrm{~mm}$ $(\square)$.

sorption. In Figure 2, the results obtained over HBEA are presented, we can show that the lowest adsorbed quantity is observed at $\mathrm{pH} 10(\mathrm{pH} \sim>\mathrm{pKa})$ where nitrophenol molecules are in the dissociated form. Then, the adsorption capacity has increased with decreasing $\mathrm{pH}$ and have become very important at $\mathrm{pH} 4$ and 5.3 (Qads around $235 \mathrm{mg} / \mathrm{g}$ ). Same results as that obtained for phenol at $\mathrm{pH}<4$ was also obtained. Similar results were obtained for ortho-chlorophenol as in the case of ortho-nitrophenol. On the other hand, SA adsorbs strongly over HBEA zeolite only at very acidic $\mathrm{pH}$. This is due to its physicochemical properties ( $\mathrm{pKa} 2.97$ ). Therefore, at $\mathrm{pH} \sim 4$, the salicylic acid molecules are in the dissociated form, which create electrostatic repulsion forces with the basic oxygen of the zeolite.

The influence of the substituent group nature on the evolution of the adsorption capacity of HFAU zeolite is visible in Figure 1 and Figure 2. It is observed that the adsorption capacity varies according to the following order:

Ortho-nitrophenol > Ortho-chlorophenol > Phenol > Salicylic acid

If we trace the evolution of solubility based on adsorption capacity (Figure SD1), we deduce that the value of the adsorption capacity of these compounds, except salicylic acid, varies linearly with the solubility.

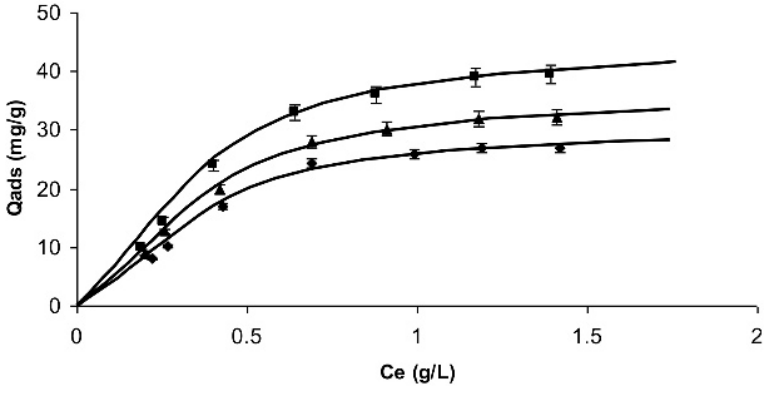

Figure 4. Adsorption isotherms of phenol in HBEA zeolite at $20^{\circ} \mathrm{C}$ $(\boldsymbol{\square}), 30^{\circ} \mathrm{C}(\boldsymbol{\Delta})$ and $40^{\circ} \mathrm{C}(\boldsymbol{\nabla})$. Lines represent fitting curves by Fowler-Guggenheim model.

However, salicylic acid has lower adsorption capacity than chlorophenol and phenol although it is much less soluble. also, at $\mathrm{pH}=10$ (Table SD1 and SD2), we observe a modification in the order of adsorption capacity of molecules, This indicates that other parameters as the effect of $\mathrm{pKa}$ have affected highly the adsorption.

This result may be related to the pka of nitrophenol which is 7.17. At pH 10, ortho-nitrophenol molecules are in the dissociated form, so adsorption is difficult and is less than that of ortho-chlorophenol whose pka is 8.49. Similar results were obtained by adsorption over activated powder carbon $[24,25]$.

\subsection{Effect of particle size}

The influence of contact time on 3 particle size ranges of BEA zeolite was investigated using particles having size of $0.05-0.07,0.2-0.4$ and $0.6-0.7 \mathrm{~mm}$. The effect of uptake was studied at using the following conditions $(\mathrm{pH}=4$, $[$ phenol $]=1 \mathrm{~g} / \mathrm{L}$, [zeolite] $=1 \mathrm{~g} / \mathrm{L}$ ).

As can be noticed in Figure 3, the equilibrium capacity was not affected by changing particle size. Although adsorption kinetics became faster with the decreasee of particle size. This fact indicates that the smaller the adsorbent particle diameter, for a given zeolite, the adsorption sites are more easily accessible and the adsorption kinetics increase.

\subsection{Effect of temperature on phenol adsorp- tion}

The influence of temperature on the adsorption of phenol was studied between 20 and $40^{\circ} \mathrm{C}$.

The results (Figure 4) indicated that adsorption capacity was decreased as temperature was increased as shown in Figure 4. This comes from the fact that phenol adsorption by HBEA is an exothermic process. Similar results were obtained over HFAU and HMOR (not presented here). 
Table 3. Parameters of Fowler-Guggenheim model and Thermodynamic parameters of phenol over HBEA zeolite at different temperature.

\begin{tabular}{lccc}
\hline$T\left({ }^{\circ} \mathrm{C}\right)$ & 20 & 30 & 40 \\
\hline \hline$K(\mathrm{~L} / \mathrm{g})$ & 1.25 & 1.17 & 1.12 \\
$W(\mathrm{~J} / \mathrm{mol})$ & -1990 & -2050 & -2060 \\
Qads $(\mathrm{mg} / \mathrm{g})$ & 40 & 32 & 27 \\
$\Delta G^{\circ}(\mathrm{J} / \mathrm{mol})$ & -536 & -402 & -312 \\
$\Delta H^{\circ}(\mathrm{J} / \mathrm{mol})$ & -3790 & -3790 & -3790 \\
$\Delta S^{\circ}(\mathrm{J} / \mathrm{mol} \cdot \mathrm{K})$ & -11.2 & -11.2 & -11.2 \\
\hline
\end{tabular}

That is also observed with the parameters of the FowlerGuggenheim model (Table 3). $\mathrm{K}$ is the equilibrium constant for adsorption of the adsorbate on an active site. It represents the interaction between the adsorbate and the adsorbent. Therefore, the highest $K$ value at $T=20^{\circ} \mathrm{C}$ $(K=1.24)$ indicates the important interaction between phenol molecules and HBEA zeolite.

While the interaction energy $(W)$ between the adsorbed molecules (Table 3 ) is negative and of similar value for the three adsorbates studied $(-2.0 \mathrm{~kJ} / \mathrm{mol})$ indicating a possible interaction between the adsorbed molecules. The equilibrium constant $K$ and the interaction energy $W$ were determined using Excel software.

The Langmuir model, the Freundlich model were also used to fit the isotherms. The parameters obtained from the isotherms are given in Table SD3. As seen from the table, although correlation coefficients $(>0.91)$ of all equations at all temperatures, the Fowler-Guggenheim model exhibited better fit to the adsorption data than the Langmuir model and the Freundlich model.

\section{Thermodynamic parameters of adsorption}

The adsorption process of phenol drifts can be summarized by the following reversible process which represents a heterogeneous equilibrium. The equilibrium constant may be expressed in terms of enthalpy change of adsorption $\left(\Delta H^{\circ}\right)$ and entropy change of adsorption $\left(\Delta S^{\circ}\right)$ as a function of temperature. The relationship between the $K$ and the temperature is given by the van't Hoff equation. $\Delta H^{\circ}$ and $\Delta H^{\circ}$ can be obtained from the slope and intercept of a van't Hoff plot of $\ln K$ versus $1 / T$.

Thermodynamic parameters, i.e., free energy $\left(\Delta G^{\circ}\right)$, enthalpy $\left(\Delta H^{\circ}\right)$, and entropy $\left(\Delta S^{\circ}\right)$ changes, were also calculated based on the adsorption isotherms using FowlerGuggenheim and are given in Table 3.

The plot $\ln K$ versus $(1 / T)$ permits to calculate the enthalpy and entropy of adsorption of phenol on zeolite. As noticed $\Delta G^{\circ}$ for all cases is negative which indicates the spontaneous nature of adsorption over HBEA. The negative values of $\Delta H^{\circ}$ confirm the exothermic nature of adsorption. The negative values of the entropy change show the sys-

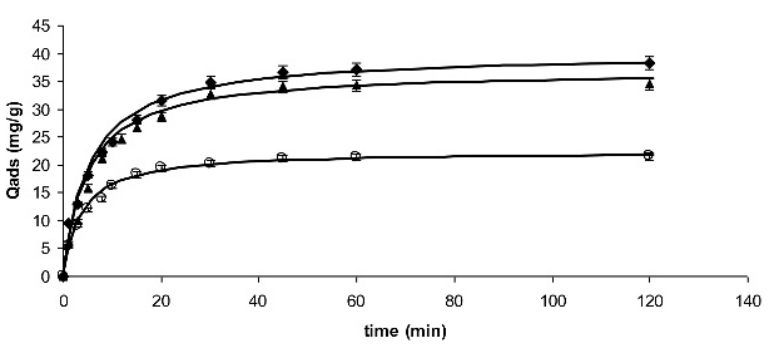

Figure 5. The adsorption kinetics of phenol with the initial concentration of $1 \mathrm{~g} / \mathrm{L}$ over HBEA $(\diamond)$, HFAU $(\boldsymbol{\Delta})$ and HMOR $(O)$. Solid line represents the simulation data based on the pseudo second-order adsorption kinetics.

tem exhibits random behaviour that have been decreased randomness at the solid/solution interface with some structural changes in the adsorbate and the adsorbent and an affinity of the adsorbent toward those molecules.

\subsection{Influence of zeolite structure}

Figure 5 shows the adsorption kinetics of phenol removal at room temperature by plotting the phenol up take capacity, $q$, versus time at $1 \mathrm{~g} / \mathrm{L}$ initial phenol concentrations. For the given concentrations, the amount of phenol adsorbed by zeolite has been increased linearly with time in the beginning (first 5 minutes), then non-linearly at a slower rate and finally a plateau has been reached after $30 \mathrm{~min}$ which is called the equilibrium time.

To distinguish the effect of structure of these zeolites, experiments were performed with various zeolites (HFAU $\mathrm{Si} / \mathrm{Al}$ ratio $=19), \operatorname{HBEA}(\mathrm{Si} / \mathrm{Al}=19)$ and Mordenite zeolite $(\mathrm{Si} / \mathrm{Al}=18)$.

Figure 5 shows that for a similar framework Si/Al ratio, HBEA and HFAU zeolites appear to be more efficient than HMOR. The high adsorption capacity of these adsorbents can be explained by the high micropore volume $(0.245)$ compared to that of HMOR (0.170). On the other hand, HBEA zeolites have smaller pore size in comparison with HFAU zeolite, so the electrostatic interaction between phenol molecules and the pores becomes greater causing better adsorption.

A study of adsorption kinetics is desirable as it provides information about the mechanism of adsorption which is important for the efficiency of the process. Linear regression is used to determine the best fitting kinetic model, and the method of least squares is used for finding the parameters of the kinetic models.

The pseudo first order kinetic constant $K$ and $q$ were calculated from the plot of $\ln (q e-q t)$ versus $t$ as shown in Figure SD2a. The pseudo second-order kinetic constant, qe and $K$ were calculated from the plot of $t / q t$ versus $t$ as shown in Figure SD2b. In addition, the intraparticle diffu- 


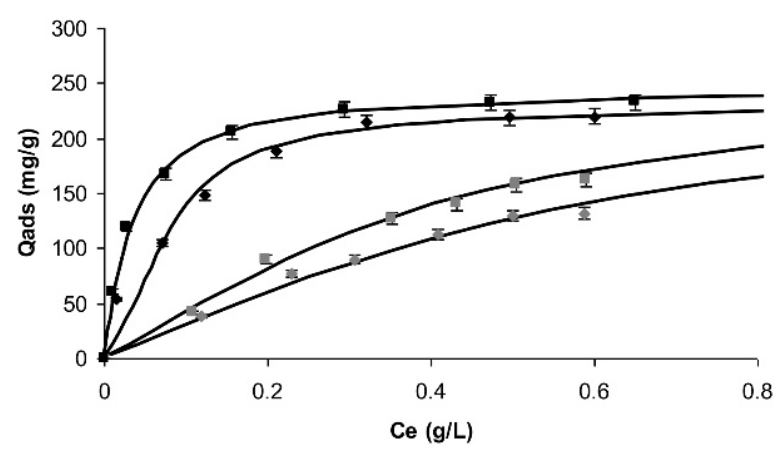

Figure 6. Adsorption isotherms obtained at $\mathrm{pH} 4$ on (ם) HFAU zeolite and $(\downarrow)$ HBEA zeolite for (black) nitrophenol and (grey) chlorophenol. Isotherms described by Fowler-Guggenheim model.

sion constant $K_{w}$ (diffusion coefficient) was obtained from the plot of $q t$ versus $t^{1 / 2}$ sorption process (Figure SD2c). The calculated kinetic constants and their corresponding coefficient of determination $\left(R^{2}\right)$ are given on the figures. From Figures S2Da, S2Db and S2Dc, it was observed that except pseudo-second-order expression, no other model provided a better fit to the experimental kinetic data.

The change in the sorption capacity with time is found to fit the pseudo-second-order equation relationship which is based on the adsorption capacity of solid phase. Because this equation is basically based on the sorption capacity, the description of sorption phenomenon suggests that the chemical reaction is rate controlling. It is indicated that these chemisorption systems involve vacancy forces through sharing or exchanging of electrons between the sorbent and the solutes. This confirms perfectly the hypothesis based on two types of sites [26-29]:

- the highly active sites: which react at the beginning time and are present in low concentrations on zeolite;

- less active sites: which react when the first sites are saturated, and are highly present at the surface of zeolite. Figure SD3 shows the different types of sites on HFAU zeolite.

Then, the influence of structure during ONP and OCP adsorption was studied. The results obtained are presented in Figure 6.

Figure 6 shows that nitrophenol and chlorophenol adsorption are favoured by using HFAU zeolite although it has the same Si/Al ratio than HBEA zeolite. This result can be explained by the difference in size between the adsorbents. Nitrophenols and chlorophenols (kinetic diameter $8.1 \AA$ ) are larger than phenols (6.7 $\AA$ ), so they face difficulties in adsorption over HBEA. HBEA with the smaller pore diameter exhibits a lower adsorption capacity than HFAU.

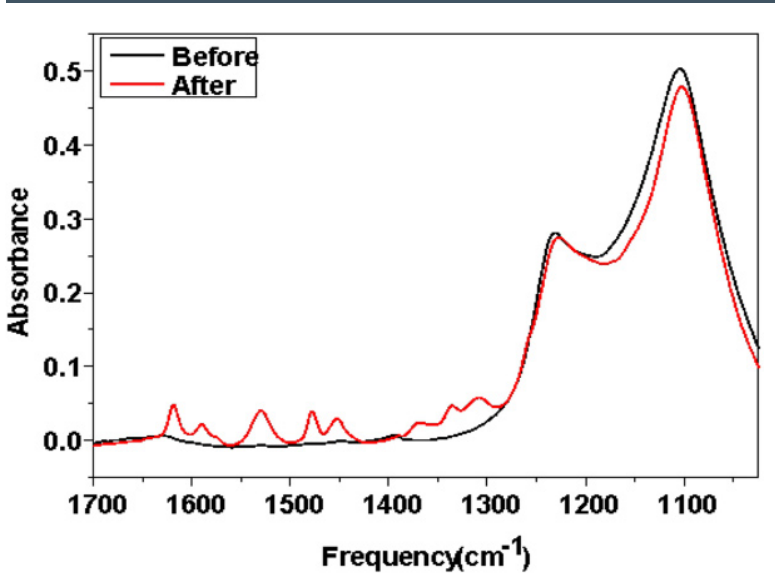

Figure 7. Infrared spectra of the HBEA zeolite before and after adsorption of nitrophenol.

\subsection{Adsorption mechanism}

\subsubsection{Infra-Red Spectroscopy}

The sorption mechanism of nitrophenol on HBEA zeolite has been investigated firstly using IR spectroscopy. FTIR spectra of HBEA is shown in Figure 7, strong absorption bands near $1200-1000 \mathrm{~cm}^{-1}$ were observed and attributed to $\mathrm{Si}-\mathrm{O}-\mathrm{Si}$ asymmetric stretching vibrations. The broad band within the $3000-3750 \mathrm{~cm}^{-1}$ interval encompassing several not-well-resolved vibrations were ascribed to hydrogen-bonded $\mathrm{SiOH}$ groups $[30,31]$. The band at $3745 \mathrm{~cm}^{-1}$ corresponds to external silanol groups.

The infrared spectra of HBEA zeolite after adsorption of nitrophenol in the $1100-1650 \mathrm{~cm}^{-1}$ region has confirmed the presence of adsorbed nitrophenol as shown in Figure 7. The bands between 1369 and $1479 \mathrm{~cm}^{-1}$ are attributed to $\mathrm{HCH}$ bending modes in nitrophenol. Infrared spectrum shows also a number of bands at 1620 assigned to $\mathrm{OH}$ deformation modes; 1590 is ascribed to $\mathrm{C}=\mathrm{C}$ aromatic stretching vibrations, and 1531 is attributed to antisymmetric $\mathrm{NO}_{2}$ stretching vibrations. While 1479 is described as $\mathrm{C}-\mathrm{H}$ in-plane bending vibrations, 1336 and $1307 \mathrm{~cm}^{-1}$ are described by symmetric $\mathrm{NO}_{2}$ stretching vibrations $\mathrm{C}-\mathrm{O}$ stretching vibrations [32]. After the adsorption, the bands corresponding to ( $\mathrm{SiOSi}$ ) between 1100 and $1225 \mathrm{~cm}^{-1}$ were strengthened. This indicates that ONP was adsorbed principally by hydrogen bonding between zeolite oxygen and the hydrogens of the aromatic cycle and the ones of functional group.

\subsubsection{Thermal desorption}

Derivative weight thermograms of HBEA zeolite before and after nitrophenol adsorption are shown in Figure 8. HBEA zeolite had one degradation peaks at $80^{\circ} \mathrm{C}$. These peaks are also visible after the nitrophenol adsorption which 


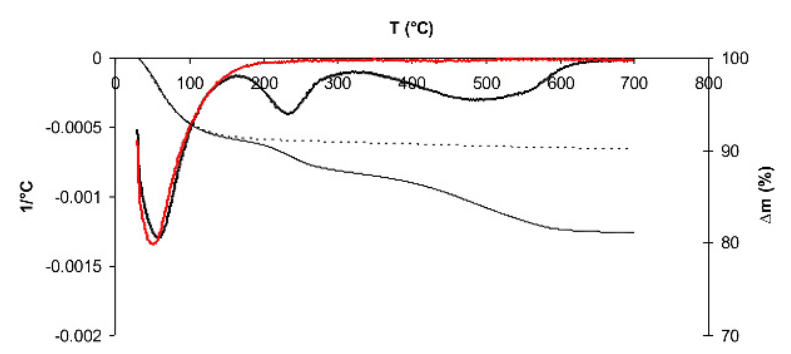

Figure 8. TGA curves of the HBEA zeolite before (--) and after (-) adsorption of nitrophenol and derivative weight curves of the HBEA zeolite before (red line) and after (black line) adsorption of nitrophenol.

always translates the loss of hydration water. It is clear from the thermogram of the HBEA zeolite after nitrophenol adsorption that the two high temperature degradation peaks between $165-600^{\circ} \mathrm{C}$ are due to the presence of nitrophenol molecules. The first peak around $235^{\circ} \mathrm{C}$ represents the beginning of desorption of nitrophenol from HBEA micropores. The second peak around $525^{\circ} \mathrm{C}$ represents the oxidation of nitrophenol linked to the acid sites in the HBEA zeolite.

The presence of two peaks around 235 and $525^{\circ} \mathrm{C}$ highlights the Possibility for phenol to adsorb on two types sites over BEA zeolite, with two separate levels of adsorption strength.

\subsection{Desorption and regeneration studies us- ing Methanol}

Desorption tests were conducted using methanol. The desorption was conducted on the spent adsorbent samples stemming from tests performed with initial $\mathrm{PhOH}$ concentrations ranging from 0.2 to $1.5 \mathrm{~g} / \mathrm{L}$ and the adsorbent loading of $5 \mathrm{~g} / \mathrm{L}$. The spent adsorbents were agitated methanol solution. After filtration and washing with deionized water, the solid was dried at room temperature and weighed. We noticed that desorption was total.

Figure 9 shows consecutive adsorption-desorption cycle data. As noticed, no significant loss (around 6\%) of adsorbent capacity was observed during five cycles of adsorptiondesorption, demonstrating that the adsorbent was suitable for the design of a continuous sorption process.

\subsection{Comparison of adsorption capacity of dif- ferent adsorbent}

Table 4 shows the parameters for phenol adsorption over different materials collected from the literature, in which the data is sorted by adsorption capacity Qads at equilibrium. Activated carbons have been shown to be the most effective adsorbents for phenol,apparently due to their surface areas,

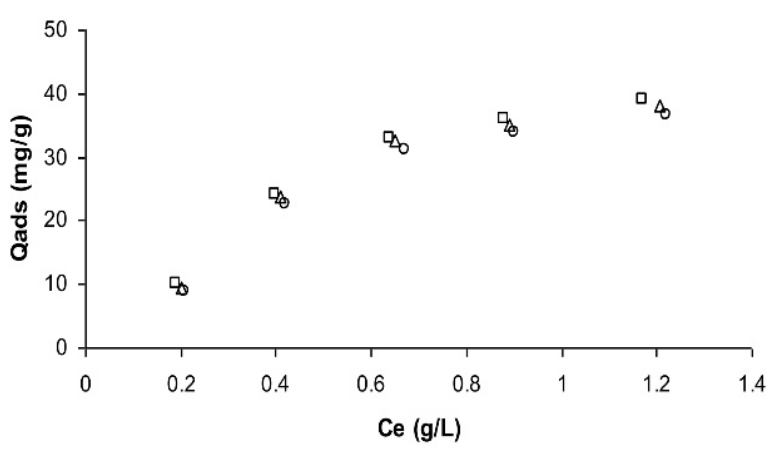

Figure 9. Effect of regeneration by methanol of HBEA zeolite after adsorption of $\mathrm{PhOH}$ : $(\square)$ fresh zeolite, $(\Delta)$ after one cycle, (O) after five cycles.

Table 4. Adsorption capacity for the adsorption of phenols on various adsorbents collected from literature.

\begin{tabular}{lcll}
\hline Adsorbent & Qads mmol/g & \multicolumn{2}{c}{ Reference } \\
\hline \hline HBEA & 0.44 & This work \\
Rice husk & 0.231 & Kennedy et al. & {$[33]$} \\
CAC & 0.075 & Radhika et al. & {$[34]$} \\
LAC & 0.102 & Srivastava et al. & {$[35]$} \\
Hexaniobate & 0.18 & Wei et al. & {$[36]$} \\
BPC & 0.945 & Dursun et al. & {$[37]$} \\
AP2.5 & 1.03 & Moreno-Castilla et al. [25] \\
XAD4 & 0.5 & Ming et al. & {$[38]$} \\
Neutralized red mud & 0.042 & Tor et al. & {$[39]$} \\
\hline
\end{tabular}

and other favourable surface properties [25, 37]. However, the carbon was partially regenerated under all the technics were used $[7,8]$. There is thus our research is focused on zeolites efficient and recyclable adsorbents.

\section{Conclusion}

In this study, the adsorption of phenol drifts from aqueous solutions was investigated using zeolites. The results indicated that adsorption capacity of the adsorbent was considerably affected by the initial $\mathrm{pH}$, the temperature and the solubility of molecule. For phenolic compound as SA with lower pKa value, along with the lower adsorption capacity on Zeolite that had been used were observed due to repulsion between dissociated molecules and the negative charge of framework oxygen of zeolite. Results obtained by FTIR proved that adsorption of phenol and its derivatives had occurred by physical interactions as Hydrogen bond interactions.

The equilibrium data were well described by the FowlerGuggenheim model and the adsorption kinetics had followed the pseudo-second-order model. The equilibrium, kinetic and thermodynamic parameters for the adsorption of phenol onto zeolites were also determined. Thermody- 
namic calculations indicated that the adsorption of phenol drifts over zeolite was spontaneous and exothermic reaction.

Regeneration tests showed that no significant loss of adsorbent capacity was observed during five adsorptiondesorption cycles.

\section{References}

[1] Fleeger J.W., Carman K.R., Nisbet R.M. Indirect effect of contaminants in aquatic ecosystem, Science Total Environments, 2003, 3170, 207-233

[2] Mukherjee D., Guha D., Kumar V., Chakroborty S., Impairement of sterodgenesis and reproduction in sexually mature Cyprinus carpio by phenol and sulphide under laboratory conditions, Aquat. Toxicol., 1991, 21, 29-40

[3] Knop A., Pilato L.A., Phenolic Resins - Chemistry, Applications and Performance, Springer Verlag, 1985

[4] Ahmaruzzaman M., Adsorption of phenolic compounds on low-cost adsorbents: Advances in Colloid and Interface Science, 2008, 143, 48-67

[5] Wolf T.A., Demirel T., Baumann R.E., Adsorption of organic polutants on montmorillonite treated with amines, J. Water Pollut. Control Fed., 1986, 58, 68-76

[6] Koubaissy B., Joly G., Magnoux P., Adsorption and Competitive Adsorption on Zeolites of Nitrophenol Compounds Present in Wastewater, Ind. Eng. Chem. Res., 2008, 47, 9558-9565

[7] Ania C.O., Menédez J.A., Barra J.B., Pis J.J., Microwaveinduced regeneration of activated carbons polluted with phenol. A comparison with conventional thermal regeneration, Carbon, 2004, 42, 1383-1387

[8] Álvarez P.M., Beltrán F.J., Gómez-Serrano V., Jaramillo J., et al., Comparison between thermal and ozone regenerations of spent activated carbon exhausted with phenol, Water Res., 2004, 38, 2155-2165

[9] Damjanović L., Rakić V., Rac V., Stošić D., et al., The investigation of phenol removal from aqueous solutions by zeolites as solid adsorbents, J. Hazard. Mater., 2010, 184, 477-484

[10] Pan B.C., Zhang X., Zhang W.M., Zhang Q.X., Adsorption of phenolic compounds from aqueous solution onto a macroporous polymer and its aminated derivative: isotherm analysis, J. Hazard. Mater. B., 2005, 121, 233-241

[11] Koubaissy B., Joly G., Batonneau-Gener I., Magnoux P., Adsorptive Removal of Aromatic Compounds Present in Wastewater by Using Dealuminated Faujasite Zeolite, Ind. Eng. Chem. Res., 2011, 50, 57055713
[12] Schick J., Daou T.J., Caullet P., Paillaud J-L., et al., Surfactant-modified MFI nanosheets: a high capacity anion-exchanger., Chem. Commun., 2011, 47, 902-904

[13] Parida S., Dash S., Patel S., Mishra B., Adsorption of organic molecules on silica surface, Advances in Colloid and Interface Science, 2006, 121, 77-110

[14] Johnston C.T., Sheng G., Teppen B.J., Boyd, S.A., et al., Spectroscopic study of dinitrophenol herbicide sorption on smectite, Environ. Sci. Technol. 2002, 36, 50675074

[15] Khalid M., Joly G., Renaud A., Magnoux P., Removal of phenol from water by adsorption using zeolites, Ind. Eng. Chem. Res. 2004, 43, 5275-5280

[16] Fowler R.H., Guggenheim E.A., Statistical thermodynamics, theory of the properties of Matter in Equil. Cambridge Press: Cambridge, U.K., 1965

[17] McKay G., McKee S., Walters H.R.J., Solid-liquid adsorption based on external mass transfer, macropore and micropore diffusion, Chem. Eng. Sci., 1987, 42, 1145-1151

[18] Weber J.R., Morris J.C., Kinetics of adsorption on carbon from solution, Journal of Sanitary Engineering Division, 1963, 89, 31-39

[19] Aksu Z., Kabasakal E., Batch adsorption of 2,4dichlorophenoxy-acetic acid,2,4-D, from aqueous solution by granular activated carbon, Sep. Pur. Technol., 2004, 35, 223-240

[20] Ho Y.S., McKay G., Pseudo-second order model for sorption processes, Process Biochem., 1999, 34, 451465

[21] Blanchard G., Maunaye M., Martin G., Removal of heavy metals from waters by means of natural zeolites, Water Res., 1984, 18, 1501-1507

[22] Lagergren S., About the theory of so-called adsorption of soluble substances, Kungliga Svenska Vetenskapsakademiens, Handlingar, 1898, 24, 1-39

[23] Dursun G., Giiçek H., Dursun A., Adsorption of phenol from aqueous solution by using carbonised beet pulp, J. Hazard. Mater. B, 2005, 125, 175-182

[24] Liu J.C., Huang C.P., Adsorption of some substituted phenols onto hydrous ZnS, J. Coil. Interface Sci., 1992, 153, 167-176

[25] Moreno-Castilla B., Rivera-Utrilla J., López-Ramón M.V., Carrasco-Marín F. adsorption of some substituted phenols on activated carbons from a bituminous coal, Carbon, 1995, 33, 845-851

[26] Wang Y., Mu Y., Quan-Bao Z., Han-Qing Y., Isotherms, kinetics and thermodynamics of dye biosorption by anaerobic sludge, Sep. Pur. Technol., 2006, 50, 1-7

[27] Kumar K.V., Pseudo-second order models for the adsorption of safranin onto activated carbon: comparison of linear and non-linear regression methods, J. Hazard. Mater., 2007, 142, 564-567 
[28] Chang C-F., Chang C-Y., Chen K-H., Tsai W-T., et al., Adsorption of naphthalene on zeolite from aqueous solution, J. Colloid Interface Sci., 2004, 277, 29-34

[29] Srivastava V.C., Swamy M.M., Malli D., Prasa B., et al., Adsorptive removal of phenol by bagasse fly ash and activated carbon: Equilibrium, kinetics and thermodynamics, Colloids and Surfaces A: Physicochem. Eng. Aspects, 2006, 272, 89-104

[30] Yoshitake H., Yokoi T., Tatsumi T., Oxyanion Adsorptions by Mono-, Di-, and Triamino-Functionalized MCM-48, Bull. Chem. Soc. Jpn., 2003, 76, 847-852

[31] Bois L., Bonhommé A., Ribes A., Pais B., et al., Functionalised Silica for Heavy Metal Ions. Adsorption, Colloids Surf. A Physicochem. Eng. Aspects, 2003, 221, 221-230

[32] Abkowicz-Bienko A.J., Latajka Z., Bienko D.C., Michalska D., Theoretical infrared spectrum and revised assignment for para-nitrophenol. Density functional theory studies, Chem. Phys., 1999, 250, 123-129

[33] Kennedy L.J., Vijaya J.J., Kayalvizhi K., Sekaran G., Adsorption of phenol from aqueous solutions using mesoporous carbon prepared by two-stage process, Chem. Eng. J., 2007, 132, 279-287
[34] Radhika M., Palanivelu K., Adsorptive removal of chlorophenols from aqueous solution by low cost adsorbent-kinetics and isotherm analysis, J. Hazard. Mater., 2006, 138, 116-124

[35] Srivastava V.C., Swamy M.M., Mall I.D., Prasad B., et al., Adsorptive removal of phenol by bagasse fly ash and activated carbon: equilibrium, kinetics and thermodynamics, Colloids Surf., A: Physicochem. Eng. Aspects, 2006, 272, 89-104

[36] Wei Q., Nakato T., Competitive adsorption of phenols on organically modified layered hexaniobate $\mathrm{K}_{4} \mathrm{Nb}_{6} \mathrm{O}_{17}$, Microporous and Mesoporous Materials, 2006, 96, 84-92

[37] Dursun A.Y., Kalayci C.S., Equilibrium, kinetic and thermodynamic studies on the adsorption of phenol onto chitin, J. Hazard. Mater., 2005, 123, 151-157

[38] Ming Z., Long C., Cai P., Xing Z., et al., Synergistic adsorption of phenol from aqueous solution onto polymeric adsorbents, J. Hazard. Mater. B, 2006, 128, 123-129

[39] Tor A., Cengeloglu Y., Aydin M., Mustafa E., Removal of phenol from aqueous phase by using neutralized red mud, J. Colloid Interface Sci., 2006, 300, 498-503 